\title{
COMPARTILHANDO PROPOSTAS PEDAGÓGICAS NA EDUCAÇÃO INFANTIL: A EDUCAÇÃO FÍSICA E UMA EXPERIÊNCIA COM BEBÊS.
}

\author{
Carmen Lúcia Nunes Vieira ${ }^{1}$ \\ carmenpila@yahoo.com.br \\ Mauricia Santos de Holanda Bezerra ${ }^{2}$ \\ mauriciast@yahoo.com.br
}

Quando tratamos de educação de 0 a 6 anos muitos autores discutem o que poderia se constituir numa Pedagogia da Infância ${ }^{3}$. O interesse pela saúde e pela qualidade de vida da infância, ao lado do levantamento de problemas como a miséria, a exploração do trabalho infantil, a violência, entre outros aspectos, levou pesquisadores à busca pela consolidação de uma Sociologia da Infância (SARMENTO, 2004; SIROTA, 2001). No diálogo com a Sociologia da Infância, estudiosos da área da Educação têm se ocupado de trabalhos sobre os ambientes educativos destinados às crianças que, segundo Cerisara e Sarmento (2004), são também construídos pelos pequenos. Esse "intercruzamento de olhares" direciona-se à constituição de uma Pedagogia da Infância cujo objeto de preocupação é a própria criança: seus processos de constituição, suas culturas, suas capacidades intelectuais, criativas, estéticas e emocionais (ROCHA, 1999). E que entre outras coisas considera a criança como sujeito de direitos. Considera a criança como "outro diferente do adulto e cujas manifestações espontâneas devem ser preservadas, especialmente no que se refere ao brincar enquanto expressão característica de seu mundo" (RICHTER, 2005, p.13).

$\mathrm{Na}$ conjuntura dessa pedagogia, entende-se, que a educação infantil deve estar orientada por uma proposta pedagógica aberta, que busca romper com modelos escolarizante que se destina a situação escolar. Nesta perspectiva uma Pedagogia da Infância diz que

\footnotetext{
${ }^{1}$ Mestre em Educação pela Universidade Federal de Santa Catarina. Membro do Núcleo de Estudos e Pesquisas Educação e Sociedade Contemporânea. Professora de Educação Física da Rede Municipal de Ensino de Florianópolis.

${ }^{2}$ Mestranda em Educação no Programa de Pós -graduação da Universidade Federal de Santa Catarina. Membro do Núcleo de Estudos e Pesquisas da Educaç ão da Pequena Infância. Professora de Educação Infantil da Rede Municipal de Ensino de Florianópolis.

${ }^{3}$ Sobre mais da Pedagogia da Infância ver em CERISARIA et al, 2002.
} 
Uma pedagogia comprometida com a infância necessita definir as bases para um projeto educacional-pedagógico para além da "aplicação" de modelos e métodos para desenvolver um "programa". Exige, antes, conhecer as crianças, os determinantes que constituem sua existência e seu complexo acervo lingüístico, intelectual, expressivo, emocional, etc., enfim, as bases culturais que as constituem com tal. Exige dar atenção às duas dimensões que constituem sua experiência social, o entorno social e as experiências das crianças como agentes e como receptores de outras instâncias sociais, definidas, portanto, no contexto das relações com os outros. (ROCHA, 2010, p.14).

No contexto da Rede Municipal de Ensino de Florianópolis (RMEF), que compartilha de tal proposição, a implicação é na direção de numa proposta de trabalho que se coloque na contramão do modelo escolarizante, pautadas na fragmentação das disciplinas escolares, já que afirma que a Educação Infantil não é escola. Mas esse distanciamento nos coloca numa situação paradoxal já que contamos, desde 1982, com profissionais da área/disciplina da Educação Física, professores horistas que atendem as crianças desde o berçário até os grupos maiores nas unidades. Com a instauração de tal Pedagogia e para atender as suas demandas os professores de Educação Física começam a freqüentar programas de formação proporcionados pela RMEF.

E conforme Viera e Medeiros (2007)

O debate acerca da especificidade da Educação Física na Educação Infantil se ampliou ao longo das últimas décadas e os estudos dos temas desses debates foram sistematizados em documentos elaborados pela própria RMEF. Tais documentos são cadernos com coletâneas de textos elaborados por consultores, que a partir da formação continuada, oferecida aos professores/as pela própria RMEF, sistematizam um texto sobre o tema debatido nos encontros das formações. Vale destacar também, nessa linha de sistematização, a pesquisa de mestrado desenvolvi da pela professora Débora Sayão, que mesmo não constituindo um documento elaborado pela RMEF é de suma importância, pois se trata de uma investigação que buscou compreender a natureza da inserção da Educação Física na Educação Infantil no contexto da RMEF. (p.56 -57).

Cabe ressaltar que tais pressupostos, sistematizados nesses documentos, refere -se a uma Educação Física que caminhe na contramão do modelo escolarizante, de disciplina escolar, que desconsidera interesses e necessidades das crianças, que determina tempo e duração de aulas e fragmenta os conteúdos. Reforça, ainda, que precisa se distanciar do modelo tradicional de Educação Física paut ado nas habilidades motoras, desenvolvimento 
motor, na recreação e na Psicomotricidade, que ainda marcam a Educação Física na Educação Infantil. Por isso avigora a necessidade de uma discussão acerca da infância.

Nesse sentido vale destacar a contribuição do Grupo Independente de Professores de Educação Física que atuam na Educação Infantil da $R M E^{4}$ - grupo de professores/s que desde 1996, tem dentre suas preocupações encaminhamentos capazes de indicar possibilidade de uma prática articulada com as discussões da Pedagogia de Infância. Mas que, sobretudo, preocupa-se com sua formação continuada e pensa questões específicas e entraves de sua própria formação para atuar com as crianças da chamada Educação Infantil.

Considerando todo esse contexto apresentamos no presente texto um relato de uma proposta de trabalho, desenvolvida, com um grupo de bebês (Grupo I), em uma Creche da Rede Municipal de Florianópolis no Norte da Ilha no ano de 2008. Vale destacar que a pretensão nesse relato de experiência é justamente enfatizar a parceria entre professora regente do grupo e professora de Educação Física, não só como justificativa e possibilidade da presença da própria especificidade da área no âmbito da Educação Infantil, mas também na contribuição na educação de crianç as tão pequenas.

Tomamos como princípio os documentos já aqui referenciados e que tratam da Educação Física na Educação Infantil, principalmente, no que dizem respeito sobre um trabalho comprometido com a totalidade do trabalho pedagógico no âmbito das un idades e não como uma disciplina escolar. Débora Sayão diz a respeito

A ideia desenvolvida anteriormente - Educação Física como disciplina escolar - limita a concepção de trabalho pedagógico pensado como uma totalidade na qual adultos, crianças, famílias e o contexto sócio-cultural são aspectos fundamentais. A superação do distanciamento entre as áreas/disciplinas que convivem no interior de uma unidade de Educação Infantil passa pela consciência de seus profissionais de que o corporativismo das formações e/ou funções é um impedimento do trabalho de qualidade. Quando pensamos em qualidade estamos vislumbrando a complementaridade entre as esferas que constituem o cotidiano das creches e NEI's. Portanto, não deve haver hierarqui as entre profissionais, crianças e famílias nos diferentes momentos do planejamento e/ou da implementação das ações. A participação das professoras regentes e auxiliares é indispensável naqueles momen tos em que o/a professor/a de Educação Física está coordenando uma atividade, assim como o

\footnotetext{
4 Maiores informações do grupo ver em: http://efinfantil.blogspot.com/2009/09/possiveis -conteudos-dos-encontrosde.html.
} 
inverso disto. Isto possibilita aos/às profissionais conhecerem melhor as crianças e construírem vínculos entre os adultos que qualificam o trabalho pedagógico. (Sayão, 2004, p. 29-33, grifos nosso).

A creche, que foi nosso campo de atuação, poss ui 10 salas de atendimento, acolhendo crianças na faixa etária de 4 meses a 6 anos, divididos em grupo, de acordo com sua idade. O horário de atendimento era das 7 horas às 19 horas, no início do ano letivo, observamos que as famílias não deixavam os bebês por muito tempo, podemos deduzir que isso ocorreu por dois motivos: primeiro porque os pais precisavam estabelecer uma relação de confiança; segundo porque até as 17 horas havia duas profissionais na sala, oferecendo às famílias um pouco mais de segurança. É importante destacar que havia apenas um grupo de bebês, diferentemente dos grupos das crianças maiores.

E neste contexto está inserido o Grupo I que passamos a situar. O grupo I era composto por 15 bebês de 4 meses a 1 ano e 11 meses. Portanto, nosso cotidiano estava inserido num sistema maior, em que os horários marcados para algumas situações de cuidado eram fortemente "imposto", tendo os "tempos" como nosso maior desafio, romper com o "tempo institucionalizado". Atuávamos com crianças - bebês - que expressavam 5 os seus desejos, anseios, vontades e necessidades, as quais eram particulares de cada um. Nossa rotina eram marcada pela hora do café, por volta das 8:15; hora do almoço, por volta das 10:40; hora do lanche, logo no início da tarde, 13:00; e por fim a janta, 15:40; além desses horários marcados pelo "sistema" tínhamos a preocupação em oferecer mais um lanche por volta das 18:00, para àqueles que ficavam na creche.

A rotina na educação infantil pode ser facilitadora no nosso dia -dia, como aponta Warschauer, apud Batista (1998, p.08),

...uma rotina de trabalho é importante para a estruturação de um grupo de
crianças (e também de adultos). Rotina de trabalho significa organização,
sistematização e disciplina. É através da rotina que o tempo e o espaço se
estruturam para a criança (a hora da roda, a hora do lanche, a arrumação das
mesas e dos materiais, etc.). A rotina orienta a criança a se organizar dentro de
um espaço e de um tempo determinado (...), porém a rotina deve ser flexível, de
modo a organizar os espaços e os tempos conforme as novas necessidades que
surjam, caso contrário ela torna-se mecânica e sem sentido (1993, p.66)

${ }^{5}$ Como aponta Schmit, 2008, p. 15. Para além da linguagem falada, as crianças pequeninas apresentam mais fortemente outras formas de comunicação - olhares, gestos, toques, balbucios, choros, gargalhadas, sorrisos, movimentos -tão complexas quanto a fala. 
Diante desses horários, nosso cotidiano também era marcado pelas trocas, os choros, os sonos, as mordidas, os banhos, os passeios, as brincadeiras, as descobertas, as superações, os sorrisos, enfim os diversos episódios que se faziam presente em nosso grupo de bebês.

Um dos nós que ainda percebemos na educação infantil é o sono das crianças na instituição, e por isso nos perguntamos: como respeitar a necessidade de cada bebê? Nossa organização do espaço foi fulcral para garantir e respeitar os "nossos" bebês. Além de três berços, deixávamos sempre disposto dois colchões e almofadas no chão, disponibilizando assim um espaço confortável para quando os desejassem.

Posto assim, uma breve caracterização do grupo e nossa rotina, iremos abordar particularmente o grupo de bebês, onde ainda carece de pesquisas, e que por esse motivo nos fez buscar ainda mais elementos que pude ssem contribuir com a nossa prática pedagógica, que abarcasse todas as discussões travadas pela área da Educação Infantil e da firmação de uma Pedagogia da Infância, compreendendo os "nossos" bebês como sujeitos sociais e de direitos, com desejos próprios, que precisavam ser ouvidos por nós.

Como defende Rocha (2010, p. 13 -14), tomamos como princípio para nossa prática pedagógica,

A consolidação de uma Pedagogia da Infância (e não uma Pedagogia da Criança, tal como nas pedagogias liberais) exige, portanto, tomar como objeto de preocupação os processos de constituição do conhecimento pelas crianças, como seres concretos e reais, pertencentes a diferentes contextos sociais e culturais, também constitutivos de suas infâncias.

Desse modo, nossa primeira ação, ainda no processo de inserção ${ }^{6}$, foi de conhecer cada bebê que pertencia ao grupo, para isso buscamos durante o período de inserção, organizar o atendimento com 7 bebês pela manhã, e 8 bebês a tarde, dessa forma, nossa aproximação com cada um deles e seus familiares se deu de forma mais intensa, em que pudemos conversar, perguntar e conhecer as diferentes formas de organização familiar ali presentes. Nesse momento buscamos confortar as famílias, pois estavam deixando pela

\footnotetext{
${ }^{6}$ De acordo com o Documento Orientador para o Período de Inserção das Crianças na educação Infantil da PMF: A inserção é um período rico de encontros e exige dos profissionais constante atenção, a fim de poderem encorajar e facilitar essa nova e importante experiência vivida pelas crianças e seus familiares. Nesse processo, cada criança manifesta seus sentimentos de maneira p rópria, o que exige a elaboração de um planejamento que privilegie o direito à atenção individual. (p.02)
} 
primeira vez, seus filhos com pesso as estranhas. Nesse processo, com um número menor de crianças possibilitou às famílias conhecerem e perceberem a estrutura física e cotidiana da instituição educativa e nós, profissionais que estaríamos diariamente com seus filhos. Procuramos também acolher cada bebê, conhecer e identificar as singularidades de cada um, seus modos de dormir, comer, andar, deitar, sentar e se expressar enfim um período que foi marcado para trazer as rotinas de casa para dentro do espaço educativo, sem repetir fielmente os rituais familiares, e que ao longo do tempo foram se alterando para um espaço coletivo e público. Compreendemos assim o Princípio da Complementaridade, cuja intenção é ter uma educação complementar a da família e não substituí -la, de modo que as duas sejam complementares para a educação da criança.

Durante esse período, a professora de educação física, era mais uma adulta no grupo, e diante de todo o movimento que estava acontecendo nesse processo de inserção, com muitos choros e desconforto por parte de al guns bebês, cujo trabalho da professora de educação física em trazer propostas que pudessem colaborar com esse período, onde as nossas atenções estavam voltadas principalmente para àqueles que estavam chorando esta atuando com aqueles que não demonstravam desconforto.

De acordo com os Princípios Pedagógicos para a Educação Infantil da Rede Municipal de Florianópolis, que compreende a Educação Infantil como espaço/tempo sócio-educativo, e como processo de trocas de experiências. A Educação Física em seu interior deve contribuir com os objetivos de ampliar os conhecimentos das crianças proporcionando-lhes os instrumentos para a apropriação crítica da cultura sistematizada pela humanidade. Além de estimular a criatividade e solidariedade, tendo como um dos princípios norteadores a brincadeira. Portanto deve ser compreendida como um tempo/espaço privilegiado para a possível ampliação dos movimentos das crianças ${ }^{7}$. E como o movimento contém a intenção de quem se movimenta, a consideramos ampla contribuição para a leitura de mundo (pelas crianças) e na construção de si mesmo ${ }^{8}$.

Foi a partir das observações do período de inserção, que percebemos como organizar o nosso trabalho, cujas propostas eram voltadas para um número menor de

\footnotetext{
${ }^{7}$ Grupo de Estudos Ampliado de Educação Física. Diretrizes curriculares para a Educação Física no ensino fundamental e na Educação Infantil da Rede Municipal de Florianópolis-SC: registro da parceria NEPEF/UFSC-SME/Florianópolis, 1993 a 1996. Florianópolis 1996.
}

${ }^{8}$ KUNZ.E. Educação Física: ensino e mudanças. Ijuí (RS): UNIJUí, 1991. 
crianças, em que poderíamos dar mais atenção individualizada, com ações intencionais, de modo que nessa relação, entre adulto e criança, o nosso olhar sensível para perceber e complexificar aquilo que já está apreendido, criando novas condições para "formar novos níveis de compreensão da real idade pela criança." (MELLO, 2007:92)

Partindo de tais premissas nossa proposta era trazer atividades que contribuíssem na ampliação dos movimentos das crianças, despertassem a curiosidade, a imaginação, o desenvolvimento das linguagens, possibilitassem in teração com todos da unidade educativa. Nossas propostas eram pautadas em todas as formas de cuidado, compreendendo o educar e cuidar de forma indissociáveis, mesmo nas ações de cuidados procurávamos conversar com o bebê que estávamos atendendo individualm ente, mas ao mesmo tempo interagíamos com os demais que estavam ali presentes, inúmeras vezes percebemos também as interações entre pares, configurando -se em momentos significativos entre as próprias crianças.

Nossa intenção ao mesmo tempo foi de construi $\mathrm{r}$ um espaço como um terceiro educador, cuja contribuição da professora de educação física, que exercia um olhar de estranhamento toda vez que entrava na sala, ajudando na reorganização do espaço e subsidiando com novos materiais, assim podíamos estar envol vidos com algum bebê, fosse num momento de cuidado ou como numa proposta individual, mas que ao mesmo tempo o próprio espaço organizado de forma intencional, agisse como um ambiente estimulante, desafiador, aconchegante e que ainda fosse favorável à explor ação de diversos materiais e que levassem as crianças a experimentar e vivenciar sensações também diversas.

Pensamos que a educação do corpo não se limita a momentos específicos. Ela acompanha, atravessa, perpassa alguns momentos da instituição, e, ao ser tomada como objeto de reflexão e atenção por parte dos adultos, favorece formas de contato, de aproximação, de comunicação que não aquelas marcada pela brevidade, pela velocidade, pelos "ponteiros do relógio" ou meramente regulada por interesses práticos.

Acreditamos que "diferentes experiências de movimento possibilitam, sobretudo, autonomia e confiança às crianças" " 9 . Porém se a Educação Física na Educação Infantil deve ser compreendida como espaço/tempo privilegiado para a possível ampliação dos moviment os

${ }^{9}$ SAYÂO. D.T. O Fazer pedagógico do/a professor de Educação Física na Educ ação Infantil. Secretaria Municipal de Educação/SME. Divisão de Educação Infantil. Prefeitura Municipal de Florianópolis/PMF . Florianópolis, 2004. 
das crianças, deve ser também, espaço/tempo de se criar experiência. Porque é preciso lembrar que, aquilo que atravessa o corpo se apresenta como algo que expõe a sensibilidade $e$ a experiência (Walter Benjamin, 1984) ${ }^{10}$. Diante disso é preciso brincar, pois há na brincadeira infantil uma dimensão da experiência e uma grande possibilidade de se experimentar a liberdade (BENJAMIN, 1984).

Certo dia, proporcionamos um passeio para os bebês, a intenção era levá -los no terreno ao lado da creche para ver de pert o uma vaca e ao mesmo tempo possibilitar que saíssem dos muros da creche. Foi preciso três adultos para quatro bebês e quatro "viagens" até o terreno. Claro que só conseguimos propor essa saída pelo fato da professora de educação física estar na sala e com a colaboração da professora readaptada. Permanecia uma professora na sala com os demais bebês, enquanto ocorria o passeio para um grupo. A vaca para alguns causou espanto e choro, o que não permitiu uma aproximação do animal. Outros já mostraram alegria, gritavam e se jogavam para tocar na vaca, o que foi permitido. ${ }^{11}$

Procuramos ao longo do ano, consolidar o grupo de bebês como pertencente a creche e por isso contemplamos a esfera da interação das crianças e adultos deste grupo junto as demais crianças e adultos que circulam no espaço da creche. Participávamos de todas as atividades coletivas (festa de aniversário, teatros, parque, refeitório e outras), para isso foi fundamental a presença de cada profissional da instituição, pois sempre buscávamos mais um a dulto para conseguir levar a todos a qualquer atividade proposta, não hesitávamos em levá -los onde quer que fosse a proposta, nossa intenção era fazer parte da unidade. Nesses casos contamos novamente com a participação da professora de educação física, al ém da diretora, do supervisor, das auxiliares de ensino, da estagiária, das profissionais de serviços gerais e demais profissionais da creche. Esse movimento que configurou o grupo I naquele ano, possibilitou aos bebês experiências que não estivessem relac ionadas a nós (profissionais do grupo), pois permitiu que fossem para outros espaços sem a nossa presença, respeitando àqueles que ainda não se sentiam seguros com outros adultos. Vários episódios de idas ao parque ou para outras salas ocorreram sem a noss a participação, profissionais da unidade buscavam os bebês para interagir e socializar com as outras crianças. Foi nesse sentido de pertencimento da unidade,

\footnotetext{
${ }^{10}$ BENJAMIN, W. Reflexões: a criança, o brinquedo, a educação. (Tradução de Marcus Vinicius Mazzari). São Paulo: Summus, 1984. 119p.

${ }^{11}$ Os registros fotográficos poderiam evidenciar esse momento, mas não temos autorização para divulgá -las.
} 
que o grupo I foi se constituindo na creche, a assim assumimos de fato a afirmação: “As crianças são de todos da unidade."

$\mathrm{Na}$ sala, as propostas oferecidas com a nossa participação eram atreladas a nossa atenção, pois pelo fato de alguns bebês não se locomoverem sozinhos, nos remetia a nossa aproximação a eles, os bebês que já se locomoviam sem auxílio de um adulto, se assim almejassem se aproximavam de nós com a intenção de pegar, tocar, puxar, morder, manusear e experimentar.

E nesse movimento de interações, descobertas e desafios dos bebês durante o cotidiano, planejávamos o nosso próximo dia, buscam os ficar atentas para aquilo que os bebês nos diziam, através do choro, dos movimentos corporais, do balbucio, do olhar, do sorriso e da fala. Refletindo e avaliando sobre aquilo que já tínhamos proposto, para planejar uma nova proposta, complexificando aq uela já realizada.

Em outros momentos, priorizávamos o atendimento individual com: uma massagem corporal, uma brincadeira na banheira, uma conversa, um passeio no colo ou segurando na mão para se equilibrar, um balanço na rede ou no balanço, na troca e e ntre tantos outros.

Vamos compartilhar aqui um episódio que julgamos demonstrar a nossa intencionalidade com as crianças e a nossa avaliação sobre a proposta do dia, de modo a replanejarmos uma nova ação. O berço foi virado de lado e coberto com alguns len çóis, que possibilitou um espaço mais escuro, para entrar e sair. As crianças percebendo esse novo espaço começaram a se aproximar e entraram no berço, com a ajuda da professora de educação física, que levantava o lençol para dar acesso ao berço. Nesse mov imento de levantar e abaixar o lençol, de achar e esconder que os bebês foram se envolvendo.

Nesse processo de refletir sobre a prática que, obedecendo a mesma organização da proposta do berço, num outro dia, a professora de educação física buscou complex ificar, fazendo com que os bebês andassem em cima das grades, aí com atenção individual para cada bebê que se aproximava e levantava os braços mostrando interesse em participar. Aqui é bom destacar que nem todos os bebês vieram participar, mesmo nós pergun tando se gostariam de andar sob as grades, e desse modo, realizamos o seu desejo, deixando -o apenas observar.

Junto ao movimento do grupo, que nos envolvia, era inevitável a troca das fraldas, já que prezávamos pelo bem estar dos bebês a troca era imediat a, mas ao mesmo tempo eles 
estavam participando da proposta sugerida pela professora de educação física, e por isso, nossa intenção era deixar com que permanecesse com os bebês na atividade proposta por pela mesma, já que o horário específico dessa modalid ade no nosso grupo era de dois períodos por semana, um matutino e outro vespertino. Então acordamos que as professoras do grupo realizaríamos as trocas, enquanto a professora de educação física permanecia com os bebês na atividade. É importante destacar qu e exceto em casos excepcionais, em que mais de dois bebês necessitassem de troca imediata, lembrando que éramos em três profissionais. É importante destacar que estávamos presentes em todas as propostas oferecidas pela professora de educação física, pois a creditamos num trabalho de colaboração entre adultos, cujo fim maior é o atendimento de qualidade às crianças pequeninas.

Nosso intento foi relatar e destacar a parceria entre a professora regente do grupo I e o profissional da educação física no cotidiano do grupo de bebês. Não apenas como mais um adulto para dar de comer e trocar fraldas, como muito ainda temos ouvido, porém como mais um profissional, com suas especificidades, para contribuir com o processo de desenvolvimento linguístico, emocional, expre ssivo, intelectual, social, cultural e corporal das crianças.

\section{REFERÊNCIAS:}

BATISTA, Rosa. A rotina no dia-a-dia da creche: entre o proposto e o vivido. Florianópolis/SC, 1998. Dissertação (Mestrado em Educação) - Universidade Federal de Santa Catarina

BENJAMIN, W. Reflexões: a criança, o brinquedo, a educação. (Tradução de Marcus Vinicius Mazzari). São Paulo: Summus, 1984. 119p.

CERISARA, A. B.; ROCHA, E. A.C.; SILVA FILHO, J. J. da. Educação infantil: uma trajetória de pesquisa e indicações para a a valiação de contextos educativos. In: 
FORMOSINHO, J. O.; KISHIMOTO, T. M. (Orgs.) Formação em contexto: uma estratégia de integração. São Paulo: Pioneira Thomson Learning, 2002, p. 203 -231.

FLORIANÓPLIS. Secretaria Municipal de Educação. Diretoria de Educ ação Infantil Orientações para o Período de Inserção das Crianças na Educação Infantil. Florianópolis, 2011.

KUNZ, E. Educação física: ensino \& mudanças. Ijuí: Unijuí, 1991. 207p.

MELLO, Suely Amaral. Infância e humanização: algumas considerações na pers pectiva histórico-cultural. Revista Perspectiva: Revista do Centro de Ciências da Educação da Universidade Federal de Santa Catarina. Centro de Ciências da Educação, Florianópolis. V. 25, n.1, p.83-104, jan,/jun. 2007.

RICHTER, A. C. Sobre a presença de u ma pedagogia do corpo na educação da infância: retratos e vozes, lugares e tempos da corporalidade na rotina de uma creche. 2005. (Dissertação de Mestrado). Florianópolis: Universidade Federal de Santa Catarina/CED/PPGE.

ROCHA, E. A.C. A pesquisa em educação infantil no Brasil: trajetória recente e perspectiva de consolidação de uma pedagogia da educação infantil. Florianópolis: CED/NUP/UFSC, 1999. 290 p. (Teses Nup, 2).

Diretrizes Educacionais pedagógicas para educação infantil . Florianópolis: 2010.

. Diretrizes Educacionais Pedagógicas para a Educação Infantil. In: Diretrizes Educacionais Pedagógicas para a Educação Infantil. Prefeitura Municipal de Florianópolis. Secretaria Municipal de Educação. - Florianópolis: Prelo Gráfica \& Editora ltda, 2010. p.11-20 
SARMENTO, M. J. As culturas da infância nas encruzilhadas da Segunda modernidade. In: CERISARA, A B.; SARMENTO, M J. Crianças e Miúdos: perspectivas sociopedagógicas da infância e educação. Porto: ASA, 2004. p. 09-31.

SAYÃO, D. T. Corpo e movimento: notas para problematizar algumas questões relacionadas à educação infantil e à Educação Física. Revista Brasileira de Ciências do Esporte, Campinas/SP, v.23, n.2, p.55-67, jan.2002.

\section{O Fazer Pedagógico do/a Professor/a de Educação Físic a na Educação Infantil.}

In: Formação em Serviço: Partilhando saberes, vislumbrando novas perspectivas. Secretaria Municipal de Educação/SME. Divisão de Educação Infantil. Prefeitura Municipal de Florianópolis/PMF. Florianópolis, 2004.

SCHMITT, Rosinete Valdeci. “Mas eu não falo a língua deles!’: As Relações Sociais de Bebês num Contexto de Educação Infantil. Florianópolis/SC, 2008. Dissertação (Mestrado em Educação) - Universidade Federal de Santa Catarina

SIROTA, R. Emergência de uma Sociologia da Infân cia: evolução do objeto e do olhar. Cadernos de Pesquisa, Mar 2001, nº. 112, p. 7-31.

VIEIRA, C.L.N; MEDEIROS, F.E. de. A produção do conhecimento em educação física na educação infantil no contexto histórico da rede municipal de ensino de Florianópolis (SC): levantamento dos eixos teóricos -metodológicos e epistemológicos em documento da rede. In: Motrivivência, Ano XIX, N.29, p. 55-77, dez./2007. 